\title{
Harapan korban trafficking terhadap dukungan pemerintah di Nusa Tenggara Timur - Indonesia: Studi kualitatif
}

\section{Trafficking victims' hopes for government support in East Nusa Tenggara - Indonesia: A qualitative study}

\author{
Awaliyah M Suwetty ${ }^{a " *}, K$ Kornelis Nama Beni ${ }^{b}$, Titin Andri Wihastuti ${ }^{c}$, Asti Melani Astari ${ }^{\mathrm{c}}$ \\ a Akademi Keperawatan Maranatha Kupang \\ ${ }^{\mathrm{b}}$ Mahasiswa Magister Keperawatan Universitas Airlangga Surabaya \\ ${ }^{\mathrm{c}}$ Fakulas Kedokteran Universitas Brawijaya Malang \\ * Corresponding author: Awaliyah M. Suwetty \\ E-mail: lyasuwetty27@gmail.com \\ Naskah Diterima : Maret 2020; Di-review : Juni 2020; Dimuat: Agustus 2020 \\ DOI 10.46888/flobamora.v3i1.33 \\ Copyright $\odot$ FLOBAMORA 2020
}

\begin{abstract}
The problem of trafficking is a global problem that has a negative impact on the survival of victims. East Nusa Tenggara is one of the provinces in Indonesia that has been categorized as an emergency area for trafficking cases. The poverty and the limited employment opportunities in the NTT region are one of the factors in the increasing cases of trafficking. Trafficking victims need attention from the government for their survival. The role of government and stakeholders to victims of human trafficking is needed to protect and guarantee the rights of victims. This study aimed to explore the expectations of victims of human trafficking regarding government support in handling victims of human trafficking in East Nusa Tenggara-Indonesia. This study used a phenomenological interpretive approach. Six participants were selected using purposive sampling method. Participants were invited to attend in-depth interviews guided by semi-structured interview guidelines. The interview then recorded then analyzed followed by Interpretative Phenomenological Analysis (IPA). The process began with reading the transcript repeatedly to find keywords from each participant, and then classified into categories and themes that have the same meaning. Five sub-themes were identified, including 1) freeing Indonesian workers from the dangers of trafficking, 2) completing the legal process of all cases in human trafficking, 3 ) preparing employment opportunities, 4) criminals in human trafficking were equally followed a legal process, 5) promoting socialization to the community. Social support from the government is essential. The government plays important role in capturing the hopes of victim, including restitution, compensation, rehabilitation and personal satisfaction in order to regain their rights. Furthermore, all policy makers, law enforcers, community organizations, professional organizations and researchers / academics should take adequate role in efforts to prevent trafficking cases.
\end{abstract}

Keywords : Trafficking victims; Human trafficking; East Nusa Tenggara region; Legal settlement; Social support.

\begin{abstract}
Abstrak
Masalah trafficking merupakan masalah global yang berdampak buruk pada kelangsungan hidup korban. Nusa Tenggara Timur merupakan salah satu provinsi di Indonesia telah dikategorikan sebagai daerah darurat kasus trafficking. Kesmikinan dan sempitnya lapangan kerja di wilayah NTT menjadi salah satu factor meningkatnya kasus trafficking. Korban trafficking membutuhkan perhatian dari pemerintah untuk kelangsungan kehidupannya.Peran pemerintah dan stakeholder kepada korban perdagangan manusia sangat diperlukan untuk melindungi dan menjamin hak korban. Penelitian ini bertujuan untuk mengeksplorasi harapan korban perdagangan manusia tentang dukungan pemerintah dalam penanganan korban perdagangan manusia di Nusa Tenggara Timur-Indonesia. Penelitian ini menggunakan pendekatan phenomenological interpretive.
\end{abstract}


Partisipan berjumlah enam orang dengan metode pengambilan sampel yaitu purposive sampling. Data diperoleh dari wawancara mendalam menggunakan pedoman wawancara semi terstruktur, seluruh data direkam. Data dianalisa dengan Interpretative Phenomenological Analysis (IPA). Prosesnya diawali dengan membaca transkrip secara berulang untuk menemukan kata kunci dari masing - masing partisipan, selanjutnya peneliti mengklasifikasikan kategori yang memiliki arti yang sama, kemudian menetapkan tema untuk semua partisipan. Hasil analisis data pada enam orang partisipan diperoleh lima sub tema yang membentuk tema harapan korban human trafficking terhadap dukungan dan keseriusan pemerintah dalam menangani kasus trafficking yaitu 1) membebaskan tenaga kerja Indonesia dari bahaya trafficking, 2) pemerintah segera menyelesaikan proses hukum tanpa memilih kasus, 3) menyiapkan lapangan kerja, 4) menangkap pelaku kejahatan trafficking, 5) meningkatkan sosialisasi ke masyarakat. Harapan dan keinginan korban akan penanganan korban tidak akan terwujud tanpa adanya dukungan sosial dari pemerintah. Pemerintah ikut berperan dalam mewujudkan harapan korban perdagangan manusia diantaranya adanya restitusi, kompensasi, rehabilitasi dan kepuasan korban perdagangan manusia untuk dapat kembali mendapatkan haknya. Pencapaian keseluruhan program pemerintah untuk mewujudkan harapan korban dapat terwujud jika seluruh pemangku kebijakan, penegak hukum, organisasi masyarakat, organisasi profesi dan peneliti/ akademisi mengambil peran penting dalam upaya pencegahan kasus trafficking.

Kata kunci: Korban trafficking; Perdagangan manusia; Wilayah Nusa Tenggara Timur; Penyelesaian hukum; Dukungan sosial

\section{Pendahuluan}

Perdagangan manusia dan eksploitasi menyebabkan berbagai masalah kesehatan global yang berdampak pada kelangsungan hidup korban perdagangan manusia (Sukran, Abas, Zimmerman, Howard, \& Oram, 2017). Indonesia merupakan negara yang pemerintahnya tidak memenuhi standar dalam perlindungan korban secara minimum, namun memiliki upaya yang tinggi guna memenuhi standar tersebut (RI, 2017). Bahaya Human trafficking telah menjadi ancaman dan menjalar ke seluruh wilayah Indonesia, salah satunya adalah Provinsi NTT. NTT merupakan provinsi yang terletak di bagian tenggara Indonesia, telah di daulat sebagai daerah asal korban tindak pidana perdagangan manusia dan telah dikatakan darurat oleh Pemerintah RI karena saat ini sebanyak 15.227 penduduk NTT dengan mayoritas perempuan berusia lebih dari 15 tahun, telah di eksploitasi untuk menjadi TKI ke beberapa Negara yang ada di kawasan ASEAN (BNP3TKI, 2018a). Penyebab utama dari permasalahan ini adalah faktor kemiskinan yang terjadi di NTT. Pengaruh kemiskinan tersebut melahirkan berbagai dampak sosial dimana kemiskinan telah menempatkan perempuan NTT sebagai individu yang rentan untuk ditindas, di intimidasi dan di eksploitasi karena budaya NTT menuntut perempuan untuk ikut bertanggung jawab dalam memperbaiki kondisi ekonomi keluarganya. (Hardum 2016)

BNP3TKI Provinsi NTT mencatat dalam kurun waktu 2013 - Juni 2018 terdapat sebanyak 4601 tenaga kerja legal dan 10.626 TKI Ilegal (BNP3TKI, 2018a). Kepolisian Daerah (Polda) NTT melalui badan Reserse dan Kriminal umum, sejak tahun 2013-2018 telah menangani 260 kasus Tindak Pidana Perdagangan Orang (TPPO), dengan jumlah korban sebanyak 748 orang, serta daerah yang menjadi target human trafficking adalah di pulau Timor (Direskrim, 2018). Penelitian dari berbagai negara menunjukkan bahwa depresi, kecemasan, Post Traumatic Stress Disorder (PTSD), melukai diri sendiri dan mencoba bunuh diri umum terjadi pada korban yang selamat dari trafficking (Ottisova, Hemmings, Howard, Zimmerman, \& Oram, 2016). Oram tahun 2016 menemukan bahwa korban trafficking di Inggris melaporkan $78 \%$ wanita dan $40 \%$ laki-laki mengalami gejala depresi, kecemasan dan PTSD (Sukran et al., 2017), hal serupa dilaporkan oleh sebuah studi tentang Human trafficking di subwilayah Greater Mekong menemukan bahwa 61\% pria, $67 \%$ wanita, serta $57 \%$ anak-anak, melaporkan adanya depresi, PTSD dilaporkan oleh $46 \%$ pria, 44\% wanita dan 27\% anak-anak (Kiss, 2015). Masalah kesehatan fisik juga ikut mengambil andil dalam masalah kesehatan yang terjadi pada korban human trafficking. Pada umumnya mereka akan mengalami masalah kesehatan seperti sakit kepala, sakit gigi, kelelahan fisik, sakit perut, pinggang dan penyakit lainnya yang menyertai (Ottisova et al., 2016). Data hasil penelusuran BNP3TKI NTT melaporkan bahwa sejak tahun 2013 - 2017 ditemukan beberapa kasus akibat trafficking diantaranya terdapat 58 kasus $(4,53 \%)$ oleh karena sakit fisik, 37 Kasus $(2,89 \%)$ mengalami gangguan kejiwaan dan 23 kasus $(1,79 \%)$ yang mengalami penyiksaan (BNP3TKI, 2018b).

Guna mengatasi dampak buruk pada korban human trafficking, Pemerintah berusaha menjalin komunikasi secara aktif dan bekerja sama dengan Lembaga masyarakat dan gugus Tindak Pidana Perlindungan orang (TPPO) untuk memberikan layanan berupa perlindungan, pengobatan dan perawatan serta rehabilitasi berbasis rumah sakit, rumah perlindungan bagi perempuan dan anak yang tersebar di provinsi dan kabupaten kota serta service center di Kedutaan Besar RI di Jakarta (Nabal, 2018). Pemerintah NTT hingga saat ini telah melakukan penanganan melalui ditempatkannya pusat pelayanan terpadu di bandara, berkoordinasi dengan P2TP2A serta bekerja sama dengan salah satu RS yang ada di kota Kupang yakni RS Bhayangkara Kupang untuk membantu melayani korban 
trafficking, namun layanan pemerintah ini masih berfokus pada penyelesaian masalah kriminalitas yang dihadapi oleh korban, tanpa memperhatikan harapan, kesehatan psikis korban.

Peran pemerintah dan stakeholder kepada korban perdagangan manusia sangat diperlukan untuk melindungi dan menjamin hak korban perdagangan manusia, Maka diperlukan penelitian untuk mengeksplorasi harapan korban trafficking terhadap dukungan pemerintah dalam penanganan korban trafficking di Nusa Tenggara Timur - Indonesia. Hasil penelitian memberikan saran kepada pemerintah untuk mengimplementasikan kebijakan dan dukungan baik penegakan hukum, pemenuhan hak korban perdagangan manusia dan pelayanan kesehatan jiwa agar mampu menekan dampak korban perdagangan manusia di Provinsi NTT. Penelitian ini hendak mengeksplorasi harapan partisipan pasca menjadi korban human trafficking terhadap dukungan pemerintah dalam penanganan korban perdagangan manusia.

\section{Metode}

Penelitian ini merupakan penelitian kualitatif dengan pendekatan Interpretive phenomenology (Nursalam 2017) dimana pendekatan ini berfokus pada eksplorasi pengalaman individu korban human trafficking selama menjadi bagian dari kejahatan trafficking. Pengambilan data dilakukan secara mendalam / indepth interview menggunakan panduan wawancara semi terstruktur. Data dianalisis dengan Interpretative Phenomenological Analysis (IPA), dimana peneliti membaca satu persatu transkrip verbatim dari masing - masing partisipan dan menggunakan bahasa tubuh partisipan untuk mendapatkan makna dari fenomena trafficking. Partisipan pada penelitian ini berjumlah 6 orang, yang dipilih melalui teknik purposive sampling dengan kriteria partisipan yaitu: 1) Warga Negara Indonesia, 2) Berdomisili di Pulau Timor Provinsi NTT, 3) Jenis kelamin, Laki - laki dan perempuan 4) Berusia 15-35 tahun, 5) Korban human trafficking,6) korban dengan penganiayaan 7) Wilayah penempatan kerja dalam negeri maupun luar negeri 8) Bebas dari PTSD (screening PTSD) 9). Bersedia menjadi responden.

\section{Hasil dan Pembahasan}

Hasil diungkapkan dengan padat dan jelas; bukan merupakan barisan data mentah (raw data). Pembahasan ditulis dengan padat dan jelas. Pada bagian ini, penulis harus mengeksplorasi signifikansi dari hasil. Hindari memasukan sitasi yang berlebihan atau mendiskusikan literatur lain yang telah dipublikasikan.

Harapan korban dalam peran pemerintah untuk mengatasi masalah trafficking tergambar dari keinginan korban akan adanya keseriusan pemerintah dalam menangani kasus trafficking. Peneliti memaknai butuh keseriusan dari pemerintah ditinjau dari persepektif korban bahwa korban ingin pemerintah lebih fokus kepada permasalahan trafficking, agar tidak ada lagi kasus dan pemerintah lebih gencar untuk memutuskan mata rantai trafficking dimulai dari pedesaan hinga ke kota. keseriusan dari pemerintah yang merupakan harapan korban yang tergambar dari lima sub tema berikut :

\subsection{Membebaskan tenaga kerja Indonesia dari bahaya trafficking}

Membebaskan berasal dari kata bebas, yang dalam KBBI diartikan sebagai merdeka (tidak dijajah, tidak diperintah atau tidak dipengaruhi oleh suatu kekuatan atau pengaruh dari orang lain/ Negara lain. Korban berharap bahwa dengan membebaskan tenaga kerja Indonesia, tidak ada lagi kasus trafficking yang menghantui masyarakat Indonesia. Dua partisipan menyebutkan dalam kutipan berikut :

"Saya maunya tidak ada lagi kasus begini, biar saya saja" (P1)

" Saya harap tidak ada lagi kasus trafficking.. Saya mau pemerintah perhatikan ini dengan serius begitu" (P3)

Korban juga mengharapkan pemerintah membebaskan tenaga ilegal dengan memulangkan semua tenaga kerja Indonesia yang masuk dengan cara ilegal,agar tidak ada lagi masalah yang mengakibatkan beban pada hidup korban yang lain. Dua partisipan menyampaikan hal ini dalam kutipan wawancara berikut :

"Pemerintah cari terus kasih pulang semua kami yang di sana, yang ilegal itu semua"(P2)

"Kalau bisa yang ilegal dipulangkan atau dibantu diurus surat - suratnya biar keadaan bisa aman" (P5)

Satu dari enam partisipan lainnya menyampaikan bahwa sangat berharap pemerintah tidak mengizinkan orang bekerja ke luar negeri, untuk menghindari kejadian trafficking ini. Dengan demikian pemerintah bisa membebaskan tenaga kerja Indonesia dari bahaya trafficking. Hal ini disampaikan dalam pernyataan berikut :

"Maunya itu pemerintah jangan kasih berangkat orang - orang yang mau kerja di Luar Negeri “(P4)

\subsection{Pemerintah segera menyelesaikan proses hukum tanpa memilih kasus}

Harapan lain dari korban trafficking adalah, pemerintah dapat membantu mengurusi proses hukum korban yang masih terus berlanjut di Negara tempat kejadian. Proses hukum yang lama akan membentuk stresor 
sendiri pada korban trafficking, baik dari segi fisik dan mentalnya. Harapan ini disampaikan oleh satu orang partisipan yang hingga saat ini, masih menunggu putusan dari kasus hukum yang dijalaninya. Berikut kutipan pernyataan korban:

"Pemerintah bisa urus saya secepatnya, agar saya bisa hidup mandiri, terbebas dari masalah,orang-orang di kedutaan juga harus membantu menyelesaikan urusan saya, biar keadilan ada buat saya,itu saja." (P3)

Korban lain juga menuturkan bahwa dalam penyelesaian masalah hukum,pemerintah bisa memperhatikan semua masalah, tidak membeda - bedakan kasus trafficking, sehingga semua korban bisa mendapatkan perhatian yang sama. Hal ini disampaikan oleh satu orang partisipan, yang dikutip sebagai berikut:

"Mungkin masalah saya biasa saja, tidak besar besar...jadi mereka tidak begitu liat..tapi itu sebenarnya sama saja, tolong sekali perhatikan kami juga" (P1)

\subsection{Menyiapkan lapangan kerja}

Harapan lainnya yang menurut korban menjadi masalah utama adalahsempitnya lapangan pekerjaan. Dengan banyaknya kasus trafficking yang terjadi saat ini,korban berharap pemerintah bisa menyiapkan lapangan kerja yang banyakagar, semua masyarakat baik dari kalangan meiningah kebawah juga bisa ikut merasakan bekerja dengan penghasilan layak di daerah sendiri. Seperti yang diungkapkan oleh dua partisipan sebagai berikut :

"Coba kalau mereka bisa siap kasih kita lahan kerja yang banyak, supaya kita kerja di keluar "(P5) sini saja, tidak perlu cari - cari lagi

"Coba mereka kasih kerjaan dengan gaji baek...biar kami tidak usah pergi merantau...kerja di kebun ini hasilnya sedikit" (P6)

\subsection{Menangkap pelaku kejahatan trafficking}

Menangkap pelaku kejahatan trafficking, sangat diharapkan oleh korban trafficking. Sebagai oknum yang telah dijerat dan ditipu, korban sangat mengharapkan kerja keras pemerintah untuk memberantas sindikat trafficking dan menangkapseluruh pelaku pelaku yang terlibat dalam transaksi tersebut. Dua dari enam partisipan mengutarakan harapannya melalui kutipan wawancara berikut

“......Saya mau ini polisi mereka, tangkap semua pelaku sampai ke dia punya akar akar, biar mereka rasa juga kita punya derita".... (P1)
“ .... Tangkap saja orang yang punya perusahaan yang kasih kerja tenaga Ilegal" (P5)

\subsection{Meningkatkan sosialisasi ke masyarakat}

Strategi terakhir yang menurut korban sangat perlu dilakukan untuk mengurangi kejadian trafficking adalah dengan meningkatkan sosialisasi ke masyarakat. Hal ini juga sangat diharapkan oleh korban kepada pemerintah. Korban berharap pemerintah lebih aktif dalam memberikan penjelasan dan menghimbau kepada masyarakat desa terkait alur pelaporan jika ditemui atau dicurigai adanya kasus perdagangan orang, seperti yang disampaikan oleh partisipan berikut ini:

"Mereka kasih nomor yang bisa dihubungi, atau ada penjelasan dari desa cara melapor kalau ada orang yang mau dijual (Alur)". (P1)

"Baik begitu na,,,mereka ajar kita cara lapor kalau ada masalah, biar kita bisa lapor kalau kita disiksadan bisa kasih belajar orang-orang kampungbiar tidak gampang kena tipu, terus ajar juga cara melapor begitu,biar bisa saling bantu" (P2).

Selain hal diatas, korban juga berharap pemerintah dapat secara terus menerus meng update kasus - kasus dan modus yang digunakan oleh pelaku trafficking, agar dapat disampaikan kepada masyarakat, sehingga meminimalkan banyaknya korban yang terjerat dalam kasus trafficking. Hal di atas seperti yang disampaikan oleh salah satu partisipan sebagai berikut :

“..... Pemerintah itu baiknya itu pergi ajar kami dikampung - kampung,,,biar kami tahu ini kasus-kasus begini, biar ko kalauada yang datang omong -omong ajak kami... kami sudah tahu mereka punya maksud" (P4)

Butuh keseriusan dari pemerintah dalam kasus trafficking dimaknai oleh peneliti sebagai upaya meningkatkan peran pemerintah yaitu tugas, kewenangan, sanksi dan aturan lainnya yang telah ditetapkan untuk mengatasi permasalahan trafficking ini akan menjadi jauh lebih baik dan lebih mudah di gunakan untuk mengatasi kejadian trafficking di kemudian hari.

Keseriusan dari peran pemerintah ini juga dapat dikatakan sebagai sebuah harapan. Harapan di definisikan oleh para ahli sebagai keinginan untuk mencapai tujuan. Menurut (Synder, 2010) harapan adalah kemampuan untuk merencanakan jalan keluar dalam upaya mencapai tujuan meskipun terdapat rintangan dan menjadikan motivasi sebagai suatu cara dalam mencapai suatu tujuan. Harapan juga 
merupakan suatu ekspektasi yang berinteraksi dengan pengharapan untuk mewujudkan kemungkinan dan berpengaruh pada tujuan (Lopez.S.J, 2009) sehingga dapat disimpulkan bahwa harapan merupakan keadaan mental positif pada seseorang dengan kemampuan yang dimilikinya dalam upaya mencapai tujuan pada masa depan. Menurut Weil (2000) terdapat beberapa faktor yang mempengaruhi harapan seseorang diantaranya dukungan sosial, kepercayaan, religious dan control. Dukungan sosial didefinisikan sebagai interaksi atau hubungan sosial yang mengakibatkan individu merasa adanya kelekatan antara seseorang ataupun kelompok, menerima kasih sayang dan perhatian (Hobfoll\& Stokes, 1988). Kepercayaan didefinisikan sebagai kemauan seseorang untuk bertumou pada orang lain dimana seseorang memiliki keyakinan kepada oran lain. Religious sendiri mengandung arti sikap dan perilaku patuh terhadap suatu kepercayaan atau keyakinan yang telah dipilih sedangkan control adalah suatu system atau alat untuk mengenalikan, memerintah dan mengatur suatu keadaan dalam system sehingga pembahasan ini akan terfokus pada pentingnya peran pemerintah dalam mengatur dan mewujudkan harapan dari korban human trafficking.

Hasil penelitian yang ditemukan pada kasus trafficking di NTT menggambarkan besarnya harapan korban terhadap pemerintah terkait masalah yang dihadapainya yaitu korban mengharapkan pemerintah membebaskan tenaga kerja Indonesia dari bahaya trafficking, Pemerintah segera menyelesaikan proses hukum tanpa memilih kasus, menyiapkan lapangan kerja, menangkap pelaku kejahatan trafficking dan meningkatkan sosialisasi ke masyarakat. Memperhatikan tingginya harapan korban kepada pemerintah, maka pemerintah selaku perangkat Negara yang tertinggi perlu mengambil tindakan tegas terhadap penindakan kejahatan ini, perlu segera melakukan recovery terhadap korban dan meningkatkan sosialisasi, pencegahan dan menerapkan beberapa intervensi untuk meminimalisir kejadian trafficking di NTT.

Harapan yang diinginkan korban tidak dapat terwujud tanpa adanya dukungan sosial dari pemerintah. Penelitian oleh (Weil, 2000) menjelaskan bahwa dukungan sosial yang positif akan meningkatkan motivasi untuk dapat mencapai harapan yang di inginkannya, namun sebaliknya tidak adanya dukungan sosial, maka akan memperburuk atau mengecilkan motivasi untuk mewujudkan harapan tersebut. Kondisi ini digambarkan (Firdiansyah, 2016) dalam hasil penelitiannya bahwa pemerintah ikut berperan dalam mewujudkan harapan korban pelanggaran HAM diantaranya adanya restitusi, kompensasi, rehabilitasi dan kepuasan korban pelanggaran HAM pada orde lama, untuk dapat kembali mendapatkan haknya. Penelitian ini ingin menggambarkan bahwa permasalahan lampau tidak dapat terselesaikan karena tidak adanya dukungan dari pemerintah, namun sebaliknya dengan tingginya dukungan pemerintah terhadap korban pelanggaran HAM hingga akhirnya harapan yang diinginkan para korban dapat terwujud.

Membebaskan tenaga kerja Indonesia dari bahaya trafficking merupakan salah satu harapan social, bahwa masyarakat khususnya korban trafficking tidak hanya memikirkan permasalahan yang dihadapinya, namun harapan ini juga berlaku yang sama bagi korban lainnya bahkan kepada masyarakat yang mungkin dapat terjerat kasus trafficking.. Harapan ini menitikberatkan pada pemusatan perhatian pemerintah terhadap kasus trafficking. Pemerintah perlu melakukan suatu reintegrasi yang melibatkan semua pemangku kebijakan/ stakeholders guna mewujudkan harapan dari para korban trafficking Menelusuri beberapa harapan korban terhadap pemerintah pada kasus trafficking, pemerintah dapat melakukan suatu proses reintegrasi yang melibatkan stakeholders untuk mewujudkan suatu perbaikan pada kasus trafficking, agar harapan yang diinginkan oleh para korban dapat terselesaikan. beberapa komponen stakeholders yang turut berperan aktif dalam mewujudkan harapan korban tersebut, dapat disajikan sebagai berikut :

Layanan Kepolisian / Police services. Polisi dalam hal ini sebagai aparat penegak hukum harus lebih mendalami proses investigasi dan meningkatkan proses pelacakan terhadap korban maupun pelaku trafficking. Pemilihan dalam penanganan kasus harus seimbang, tanpa memilih kasus yang memiliki potensi dalam arti apakah kasus tersebut butuh penananganan serius ataukah hanya sebatas investigasi tanpa ada tindak lanjut. Follow up terhadap kasus harus terus dilakukan untuk memastikan keamanan dan keselamatan korban dan keluarga untuk meminimalkan factor resiko yang mungkin dapat mengancam keselamatan dari para korban trafficking. Menurut uraian guideline for Assisting Victim Of Human Trafficking In East Africa Region menuturkan bahwa peran polisi pada kasus trafficking memiliki porposi yang sangat tinggi mulai dari interview pada awal kejadian hingga memberikan perlindungan kepada korban (Moses \& Radoslaw, 2011). Kepolisian juga harus meningkatkan kerjasama dengan penegak hukum lainnya seperti kejaksaan atau kehakiman, untuk proses peradilan hukum bagi pelaku trafficking. Beberapa bukti peningkatan kinerja dan kerjasama antara polisi, penegak hukum lainnya dengan pemerintah terlihat dengan adanya kebijakan dan perundang - undangan dari segi hukum untuk menjerat pelaku dan kebijakan kesehatan untuk perlindungan hak - hak korban diantaranya adalah adanya undang - undang dan peraturan presiden untuk kasus tindak pidana, menyiapkan gugus TPO di tingkat pusat hingga daerah serta layanan 
pengaduan yang telah disebarkan ke berbagai wilayah.

Departemen Layanan Sosial / social welfare services, pemangku kebijakan ini dapat meningkatkan layanan kepada para korban trafficking melalui peningkatan dan pemantauan/ tindak lanjut kesejahteraan pada korban trafficking. Melalui layanan social ini, korban trafficking dapat meningkatkan ketrampilan/ Skill yang mumpuni, sehingga korban dapat kembali survive dalam melanjutkan kehidupan ekonomi baik bagi dirinya dan keluarganya (Hassinger 2018) Kondisi ini akan sangat membantu pemerintah dalam meningkatkan fungsi ekonomi pemerintahan. Dengan sempitnya lapangan pekerjaan yang ada, korban masih tetap dapat meningkatkan kehidupan melalui skill dan kompetensi yang telah dikembangkan oleh layanan social masyarakat. Layanan departemen social juga dapat dikembangkan dengan menyusun kebijakan, program, kegiatan dalam bentuk rencana aksi nasional dan rencana aksi daerah guna menyentuh persoalan trafficking sampai menemukan solusi dan alternatif bagi korban, menyiapkan rumah perlindungan serta melakukan rehabilitasi korban (Cohen, S., Underwood, L.G., \& Gottlieb 2012)

International organizations. Pemerintah NTT dapat melakukan kerjasama dengan berbagai Organisasi internasional Di beberapa Negara. Organisasi Internasional ini dapat memainkan peran penting dalam reintegrasi korban. Organisasi ini dapat menyediakan platform untuk kerja sama antara berbagai lembaga dan dapat terlibat aktif secara langsung dalam mengembalikan korban ke negara atau komunitas asalnya. Melalui kerjasama dengan berbagai Organisasi Internasional Pemerintah telah ikut berpartisipasi dalam pembebasan korban trafficking yang berada di wilayah negara lain.

Organisasi Kemasyarakatan/Civil society organizations. Organisasi masyarakat juga memainkan peran pendukung utama bagi pemerintah dalam bantuan langsung dan reintegrasi korban trafficking. Organisasi masyarakat merupakan lingkup terdekat dengan masyarakat yang memiliki berbagai keterbatasan seperti tingkat Pendidikan, tuntutan kehidupan dan berbagai keterbatasan lainnya, hal ini yang memudahkan masuknya gangguan trafficking kepada masyarakat (Moses \& Radoslaw, 2011). Dalam menjalankan tugas dan kewenangannya, organisasi masyarakat ini perlu mendapatkan dukungan kuat dari petugas kesehatan, pekerja sosial, petugas pengembangan masyarakat, dan pihak berwenang setempat untuk mengintegrasikan kembali korban secara efektif. Penyebaran atau sosialisasi kepada masyarakat terkait human trafficking, perlu ditingkatkan oleh organisasi masyarakat baik di tingkat desa, kelurahan, kecamatan, kabupaten hingga ke Provinsi melalui berbagai kegiatan kemasyarakatan seperti musyawarah desa, Arisan kelompok masyarakat, kegiatan keagamaan dan berbagai kegiatan masyarakat lainnya untuk mencegah kasus trafficking dan membantu pemulihan bagi korban trafficking.

Pencapaian keseluruhan program pemerintah untuk mewujudkan harapan korban dapat terwujud jika seluruh pemangku kebijakan, penegak hukum, organisasi masyarakat, organisasi profesi dan peneliti/ akademisi mengambil peran penting dalam upaya pencegahan kasus trafficking. Dengan kesiapsiagaan semua pihak diharapkan apa yang menjadi harapan korban boleh dapat diwujudkan oleh semua pihak sebagai bentuk dukungan sosial kepada korban trafficking.

\section{Kesimpulan}

Terwujudnya harapan korban trafficking sangat bergantung pada semua pihak yang terlibat dalam pemerintahan. Pemangku kebijakan, penegak hukum, organisasi masyarakat, Organisasi International, organisasi profesi dan peneliti/ akademisi mengambil peran penting dalam upaya pencegahan dan rehabilitasi serta reintegrasi pada kasus trafficking. Peningkatan kerjasama lintas sector dan stakholders yang tinggi, akan menunjang pemerintah untuk menyelesaikan permasalah trafficking yang dihadapi oleh masyarakat dan dapat menuntun korban agar dapat kembali survive di kehidupan selanjutnya.

Dari sisi preventif hasil penelitian ini memberikan masukan kepada pemerintah agar menyiapkan lapangan pekerjaan yang memadai didaerah karena faktor utama motivasi korban human trafficking adalah faktor ekonomi yaitu kemiskinan. Penguatan ekonomi keluarga dan sosialisasi untuk meningkatkan kesadaran mengenai alternatif pekerjaan yang legal perlu dilakukan oleh pemerintah dan pihak-pihak terkait untuk mencegah terjadinya korban human trafficking. Penelitian ini juga memberikan masukan kepada Pemerintah agar menyusun konsep kebijakan diplomasi dan kerjasama dengan negara lain yang bertujuan untuk melindungi tenaga kerja dari eksploitasi dan bahaya lebih lanjut serta memiliki akses ke perawatan fisik dan psikologis yang memadai.

\section{Ucapan Terima Kasih}

Terimakasih disampaikan secara khusus kepada Universitas Brawijaya, Universitas Airlangga dan Yayasan Maranatha NTT, semoga hasil penelitian ini dapat memberikan kontribusi untuk Pemerintah Provinsi NTT dalam menangani masalah Human Trafficking.

\section{Referensi}

Abas, M., Nicolae V, O., M., P., V.I, G., Carolina, T., \& S., O. (2013). Risk factors for mental disorders in women survivors of human trafficking: a historical cohort study. $B M C$ Psychiatry, 13 : 204. Retrieved from 
http://www.biomedcentral.com/1471-

\section{$244 \mathrm{X} / 13 / 204$}

BNP3TKI. (2018a). Data Penempatan dan Perlindungan TKI. Retrieved from http;//www.bnp2tki.go.id/uploads/data/daa_0802-2017_111324_data-P2TKI_tahun 2016.pdf

BNP3TKI. (2018b). Laporan Tahunan Kasus CTKI/TKI NTT. Retrieved from

Cohen, S., Underwood, L.G., \& Gottlieb, B.H. 2012. "Social Support Measurement and Intervention: A Guide for Health and Social Scientists." New York: Oxford University Press.

Daniel, E. S. R. (2016). Human Trafficking di NTT. Social Work Jurnal Care, Vol. 3, No. 3, Tahun 2015.

Direskrim. (2018). Laporan Tahunan TPPO. Retrieved from

Firdiansyah. (2016). Peran dan Harapan korban untuk penyelsaian pelanggaran berat HAM di masa Lalu. Jurnal HAM Vol XIII ; Komnas HAM Indonesia.

Hardum, Edi. 2016. Perdagangan Manusia Berkedok Pengiriman TKI. Vol. 1. yogyakarta: Ar-Ruzz Media.

Hassinger, Charles D. 2018. "The Impacts of Family Support of the Victims of Sex Trafficking. from University of Minnesota, Morris.” University of Minnesota, Morris.

Judge, S. M., \& Boursaw, B. (2018). The Impact of the Trafficking Victims Protection Act of 2000 on Trends in Federal Sex Trafficking Cases. Criminal Justice Policy Review, Volume: 29 issue: 8, page(s): 823-848 Article first published online: June 24, 2016; Issue published: October 1, 2018 doi:https://doi.org/10.1177/0887403416655430

KBBI. (Ed.) (2015) Kamus Besar Bahasa Indonesia, Edisi V. Jakarta: Kementerian Pendidikan dan Kebudayaan Republik Indonesia.

Lemma, D. G., Alemayehu, W. Y., Yigzaw, K. G., AzeleTelake, Tilman, B., \& Hajo, Z. (2018). Socio economic, trafficking exposures and mental health symptoms of human trafficking returnees in Ethiopia: using a generalized structural equation modelling. International Journal of Mental Health Systems, 1262.

Livia Ottisova, P. S., Hitesh Shetty, Daniel Stahl, Johnny Downs,Sian Oram. (2018). Psychological consequences of child trafficking: An historical cohort study of trafficked children in contact with secondary mental health services. PLOS ONE 13:3 doi:https://doi.org/10.1371/journal.

Lopez.S.J. (2009). Hope Theory, Research, and Applications;positive Psychological assesment. Kansas: APA.

Nabal, A. R. J. (2018). Telaah Human Trafficking DiIndonesia. Lembaga Kajian, Penelitian, dan
Pengembangan Pengurus Pusat PMKRI St. Thomas Aquinas.

Nations, U. (2014). Human Rights and Human Trafficking (Vol. Sheet 36). New York and Geneva: United Nations.

Nursalam. 2017. Metodologi Penelitian Ilmu Keperawatan: Pendekatan Praktis. Edisi 4. Jakarta: Salemba Medika.

Ottisova, L., Hemmings, S., Howard, L. M., Zimmerman, C., \& Oram, S. (2016). Prevalence and risk of violence and the mental, physical and sexual health problems associated with human trafficking: an updated systematic review. Epidemiology and Psychiatric Sciences, 25 , 317-341. doi:doi:10.1017/S2045796016000135

Radoslaw, O. T. M. M. L. (2011). Guidelines for Assisting Victims of Human Trafficking in theEast Africa Region. Guidelines for Assisting Victims of Human Trafficking in theEast Africa Region. I. O. F. Migration. Switzerland, International Organization for Migration.

RI, K. (2017). Laporan Tahunan Perdagangan Orang 2017. Retrieved from Jakarta: https://id.usembassy.gov/id/laporan-tahunanperdagangan-orang-2017/

Sukran, A., Abas, M., Zimmerman, C., Howard, L. M., \& Oram, S. (2017). Mental health and human trafficking:responding to survivors' needs. BJPSYCH International 14.

Synder, C. R. (2010). The Psychology of Hope. New York: The Free Press.

Weil, C. M. (2000). Exploring Hope in Patients end stage renal disease on Chronic Hemodialysis. ANNA journal, Vol.27.

W.Creswell, J. (2014). Penelitian Kualitatif \& Desain Riset. Yogyakarta: Pustaka Pelajar.

W.Creswell, J. (2016). Research Design ; Pendekatan MetodologiKualitatif, Kuantitatif dan Campuran (Vol. Edisi 4). Yogyakarta: Pustaka Pelajar. 
